\title{
OS VÍCIOS E AS VIRTUDES NA CAPPELLA DEGLI SCROVEGNI: UMA APROXIMAÇÃO DAS QUESTÕES FILOSÓFICAS PRESENTES NO SÉCULO XIII
}

\section{THE VICES AND THE VIRTUES AT CAPELLA DEGLI SCROVEGNI: AN APPROXIMATION OF THE PHILOSOPHICAL QUESTIONS PRESENTS IN THE XII CENTURY}

\author{
Meire Aparecida Lóde Nunes ${ }^{1}$ \\ Terezinha Oliveira ${ }^{2}$
}

\begin{abstract}
Resumo: Nosso objetivo neste texto é refletir acerca da organização decorativa da Cappella degli Scrovegni, pintada por Giotto (1267-1337). O interesse é decorrente dos apontamentos de Baxandall (2006) de que o objeto artístico é a solução consciente de problemas impostos ou vivenciados pelo artista e das informações de Castelnuovo (1996) de que Giotto possibilitou ascensão de seu oficio pelo reconhecimento da intelectualidade de suas obras. Assim, constróise a hipótese de que a organização dos afrescos na Cappela degli Scrovegni pode ser aproximada das questões filosóficas presentes na sociedade de Giotto. Para realizar esse exercício trazemos o pensamento de Tomás de Aquino. Nossa opção deve-se ao fato de que os dois são referências em suas respectivas áreas, Giotto na arte e Tomás de Aquino na filosofia/teologia escolástica. Os feitos desses dois italianos ganham proporções ainda mais significativas à medida que os analisamos como 'mestres' que contribuíram para a educação de sua época, conduzindo os homens a transformar a potência do conhecimento em ato. Esse olhar para Giotto, nos auxilia a fortalecer os estudos imagéticos como importante perspectiva de estudo em História da Educação. Giotto, não apenas decorava ambientes, mas participava efetivamente da educação dos homens de seu tempo.
\end{abstract}

Palavras-chave: Historia da Educação; imagem; Giotto di Bondone; escolástica.

Abstract: Our goal in this text is to meditate about the decorative organization of the Capella degli Scrovegni, painted by Giotto $(1276-1337)$. The interest is due to the appointments of Baxandall (2006) in which the artistic object is the conscious solution of the problems inflicted or lived by the artist and about the Castelnuovo (1996) information's that Giotto made possible the rise of his craft by the recognition of the intellectuality in his works. In this way, it is build the hypothesis that the frescoes' organization in Capella degli Scrovegni can get close to the philosophical questions present at Giotto's society. To accomplish this exercise, we show Tomas de Aquino's thought. Our option is due to the fact that both are reference at their respective areas. Giotto in arts and Tomas de Aquino at philosophy/scholastic theology. The deeds of these both Italians earn proportions even more significant so far as we analyzed them as "masters" that contributed to the education at their age, conducting men to transform the potency of knowledge into act. This look to Giotto, help us to strengthen the image studies as an important perspective at studies in History of Education. Giotto not only decorated environment, but participated effectively on the education of men at his time.

Key-words: History of Education; image; Giotto di Bondone; scholastics.

Nosso objetivo neste texto é refletir acerca da organização decorativa da Cappella degli Scrovegni, especificamente o ciclo dos vícios e das virtudes, pintada por Giotto em 1306 na cidade de Padova/Itália. Como é amplamente divulgado, as imagens na Idade Média

\footnotetext{
${ }^{1}$ Doutora em Educação pela Universidade Estadual de Maringá. Professora da Unespar - Campus de Paranavaí. E-mail: meirelode@gmail.com.

${ }^{2}$ Pós-Doutora em Filosofia da Educação pela Universidade de São Paulo. Bolsista Produtividade em Pesquisa 1D do CNPq. Professora da Universidade Estadual de Maringá. E-mail: teleoliv@ gmail.com.
} 
desempenharam um importante papel didático devido a seus temas e narrativas, mas também podiam sugerir outras questões que não estavam explicitas. Recordamos o pensamento de Baxandall (2006) de que o objeto artístico que recebemos é o produto, ou a solução, de um problema imposto ou vivenciado pelo autor/artista. Assim, supomos que entre os problemas que os afrescos da Cappela degli Scrovegni respondem podem ser inserido o desejo do artista de retirar seu oficio das artes mecânica aproximando-o das atividades intelectuais. Nossa hipótese é construída por meio das informações de Castelnuovo (1996) que menciona a existência de uma hierarquia entre os ofícios na Idade Média. De acordo com o autor, a pintura ocupava uma posição inferior comparada com outros ofícios como arquitetura, ourivesaria e escultura. Essa situação começa a se modificar com Giotto, que é valorizado por intelectuais renascentistas - como Dante, Boccaccio e Petrarca - não por suas habilidades manuais, mas sim pela intelectualidade de suas obras. Considerando a indicação de Baxandall de que o objeto artístico é a solução consciente de um problema e as informações de Castelnuovo de que Giotto possibilita ascensão da pintura na hierarquia dos ofícios medievais, supomos que a Cappela degli Scrovegni pode ser a resposta do artista ao problema de depreciação do oficio de pintor.

De acordo com essa perspectiva, construímos nossa proposta de investigar a organização dos afrescos pintados na Cappela degli Scrovegni aproximando-as de pensamentos/questões filosóficas presentes no contexto de Giotto. Para realizar esse exercício trazemos o pensamento de Tomás de Aquino. A opção por Tomás de Aquino deve-se ao fato de que os dois personagens são referências em suas respectivas áreas, Giotto na arte e Tomás de Aquino na filosofia/teologia escolástica, além de terem sido contemporâneos e de origem italiana: Tomás de Aquino nasceu em 1225 e Giotto em 1267. Ambos assistiram ao renascimento das cidades, ao desenvolvimento comercial italiano e indicaram em suas obras a consciência do nascimento de um homem que clamava por outra visão de mundo, a qual deveria ser condizente com sua realidade. Tomás de Aquino, um monge que propiciou a renovação teológica ao retomar a filosofia aristotélica e cristianizá-la; Giotto, um artesão que renovou as representações artísticas de inspiração bizantina e humanizou as tradicionais narrativas bíblicas. Os feitos desses dois italianos ganham proporções ainda mais significativas à medida que os analisamos como grandes 'mestres' que contribuíram para a educação de sua época, conduzindo os homens a transformar a potência do conhecimento em ato. Considerar Tomás de Aquino como mestre não causa nenhuma estranheza, todavia, a princípio, não se poderia afirmar o mesmo de Giotto, que também é chamado de mestre, mas na acepção de mestre artesão, o que, em sua compreensão literal, não contempla o ensino. No entanto, se assumirmos o conceito de mestre apresentado por Lauand (2004) como aquele que 'mostra', por conduz o processo de aprendizagem por meio de sinais que possibilitam o aluno a adquirir por si mesmo o conhecimento, podemos, extrapolar o sentido da ação do artesão e entender Giotto como 'mestre' de forma análoga a Tomás de Aquino. Esse olhar para Giotto como mestre, nos auxilia a entender e fortalecer os estudos imagéticos como uma importante perspectiva de estudo em História da Educação. Giotto, não apenas decorava ambientes, ele participava efetivamente da educação dos homens de seu tempo.

Iniciamos nossa abordagem contextualizando o local onde estão as obras aqui mencionadas - Cappella degli Scrovegni - e os prováveis problemas vivenciados pelo artista no momento de sua criação. Na sequência nos dedicamos a análise da organização dos afrescos, em particular aqueles que compõem o ciclo dos vícios e das virtudes pintados nas paredes da capela.

\section{Cappella Degli Scrovegni e o contexto de sua construção}


Baxandall, ao refletir sobre as intenções dos artistas e suas obras, aponta a impossibilidade da precisão nas tentativas de reconstruí-las e, mesmo, explicações sobre os fatos, pensamentos e técnicas empregadas pelos artistas na construção de suas pinturas. Isso porque, "[...] A verdade é que lidamos com o resultado pronto de uma atividade cujo processo não temos condições de recontar" (BAXANDALL, 2006, p. 47). Para amenizar as imprecisões, a proposta seria tentar reconstruir o problema que gerou a construção do objeto associando-o às circunstâncias de sua efetivação. Para Baxandall, o objeto que temos em mão é o produto da solução do artista/autor diante de um problema, mas ele próprio ressalva:

Mas a reconstrução não refaz a experiência interna do autor; ela será sempre uma simplificação limitada ao que é conceituável, mesmo que opere numa estreita relação com o quadro em si, o que nos proporciona, entre outras coisas, modos de perceber e de sentir. Nossa atividade será relacional - trataremos das relações entre um problema e sua solução, entre o problema e a solução com o contexto que os cerca, da relação entre nossa interpretação e a descrição de um quadro, da relação entre uma descrição e um quadro. (BAXANDALL, 2006, p. 48).

Inspirados pelo autor, olhamos para os fatos relacionados à construção da Cappella dell'Arena, ou Cappela degli Scrovegni - considerada a guardiã de uma das maiores riquezas artísticas do trecento italiano, os afrescos da fase madura de Giotto di Bondone - com o propósito de pensar sobre os possíveis problemas presentes no momento de sua construção.

A história da Cappella de Arena tem início em 1300, quando Enrico Scrovegni adquiriu de Manfredo Delesmanini, filho de Guezili de'Dalesmanini - patriarca de uma nobre família decadente - as ruínas da antiga arena romana de Padova. O novo proprietário era um rico banqueiro padovano, nono e último filho de Reginaldo Scrovegni, homem que tinha acumulado um grande capital com atividades comerciais que se estendiam de Veneto a Toscana. Pisani (2011, p. 13, grifo do autor) descreve Reginaldo como "[...] típico representante daquela negligente classe empreendedora e financeira (o dantesco nova gente de ganhos rápidos), que, naquele momento, não tinha escrúpulos de emprestar dinheiro a altos juros ${ }^{3}$ ". Por isso, o poeta Dante lhe teria reservado o sétimo círculo do inferno na Divina Comédia, passagem usada com frequência para identificar o banqueiro de Padova como usurário.

Em vida, Reginaldo ambicionava um papel político à altura de sua condição econômica; após sua morte, Enrico herdou o desejo do pai e propôs-se a realizá-lo por meio de ambiciosos projetos, dentre os quais seus dois matrimônios com mulheres de famílias nobres italianas e a compra do terreno da antiga arena romana. De acordo com Pisani (2011), com esses investimentos, por sua grandeza e magnificência, Enrico visava claramente impressionar os habitantes e pessoas de poder, na expectativa de que isso lhe trouxesse um frutífero retorno político. Esse desejo pode ser atribuído à condição em que viviam os Scrovegni em Padova. De acordo com Jacobus (2008), a cidade de Padova tinha um governo comunal dominado por uma aristocracia urbana de fortes raízes feudais e valores militares, e não eram essas as origens dos Scrovegni. Assim, as tentativas de ascensão da família à oligarquia padoveza caracterizou-se como um processo de grandes tensões, conforme narraram seus contemporâneos. Jacobus

\footnotetext{
3 Traduzido por nós de: "Rinaldo era il tipico rappresentante di quella spregiudicata classe imprenditoriale e finanziaria (la dantesca gente nuova e' subiti guadagni), che all'occorrenza non si faceva scrupolo di prestare denaro ad alti interessi".
} 


\section{Notandum 42 set-dez 2016 - CEMOrOC - Feusp / IJI-Univ. do Porto DOI: http://dx.doi.org/10.4025/notandum.42.6}

(2008) informa que, em uma genealogia feita por Giovanni da Nono e outros associados a Zamboni e Andrea Fava Sochi, os Scrovegni são descritos como:

[...] sendo de baixa ou comum origem. Tais zombarias ainda eram consideradas vários séculos depois, quando historiadores locais, escrevendo sobre as tradições da glorificação cívica, tentaram fabricar origens nobres para esta família que desempenhou papel tão importante no embelezamento da cidade. Entretanto, essas róseas anotações não resistiam aos exames minuciosos dos invejados caminhos que a família Scrovegni havia realizado; a família não era contemplada na lista definitiva de nobres e magnatas do estatuto de $1278^{4}$. (JACOBUS, 2008, p. 3-4, grifo do autor).

Empenhado na busca por respeito social, Enrico investiu na construção da capela. O jovem Scrovegni é descrito por Pisani (2011) como inteligente, esperto e capaz de gerenciar situações muito complicadas e também como um homem de muitos relacionamentos que conhecia a arte de lidar com os poderosos. Wolf (2007) nos auxilia a compor a figura de Enrico ao informar que ele próprio se denominava como o 'nobre e poderoso cavaleiro D. Henricus Scrovegnus Magnificus, cidadão de Pádua'. Mais: “[...] seu contemporâneo, Giovanni da Nono, o descrevesse como um hipócrita fraudulento. Do seu ponto de vista, até Enrico se vira impossibilitado de afastar de si próprio toda a suspeita de usura" (WOLF, 2007, p. 30).

A propriedade adquirida por Enrico continha uma pequena igreja que era o destino final da procissão que acontecia no dia 25 de março na festa da Anunciação de Maria. Basile e Borsella (2013, p. 12) confirmam essa informação de que, “[...] pelo menos desde 1278, havia uma igreja onde a festa da Anunciação era celebrada a cada 25 de março com uma procissão solene e uma peça de teatro milagrosa ${ }^{5}$ ".

Aproveitando a realização desse tradicional evento em sua propriedade e sob a alegação de que desejava redimir os pecados usurários do pai, Enrico escondeu da população padovana suas ambições sociais e se empenhou na construção da Cappella da Arena. Assim, solicitou que o Bispo Ottobono dei Razzi autorizasse a construção, o que foi concedido em 31 de março de 1302. Na época, os vizinhos Erimitani não se opuseram à construção da capela, já que ela não seria aberta a reuniões públicas, como estava bem claro no documento de concessão: "[...] construir uma pequena igreja, a modo de um oratório, somente para si mesmo, a mulher a mãe e a família, à qual não pudesse ter acesso o povo"6 (PISANI, 2011, p. 17). A capela foi construída em um curto espaço de tempo. Dois anos após o início da construção ela já estava pronta; foi quando Enrico, desafiando todos os acordos anteriores, abriu-a ao público e, em março de 1304, conseguiu do papa Benedito XI a autorização para transformar a capela privada em pública. Wolf (2007), explica que isso não agradou os monges Erimitani que protestaram, mas em vão. A contragosto dos monges, Enrico tornou pública a capela e exibiu à comunidade padovana a rica decoração que havia sido confiada a dois grandes artistas da época: Giovanni

\footnotetext{
${ }^{4}$ Traduzido por nós de: “[...] as being of low or commom origen. Such jibes were still considered serious later, when local historians wrinting in a tradition of civic glorification tried to fabricate noble origens for the family that had played such an important role in the beuatification of their city. However, their rosy accounts do not stand up to scrutiny in the way that the jaundiced views of the Scrovegni's contemporaries do; the family does not feature in a near-definitive list of nobles and magnates appender to a statute of 1278".

${ }^{5}$ Traduzido por nós de: "In the area acquired by Enrico Scrovegni had stood, since at least 1278, a church where the feast day of the Annunciation was celbrated every March 25 with a solem procesion and a miracle play".

${ }^{6}$ Traduzido por nós de: “[...] edificare una piccola chiesa, a mo' di oratorio, soltanto per sé, la moglie, la madre e la famiglia, cui non potesse accedere il popolo".
} 
Pisano e Giotto di Bondone. Pisano, renomado escultor, ficou encarregado dos ornamentos da abside e Giotto, de afrescar as paredes da capela.

A capela de $21.50 \mathrm{~m}$ de comprimento por $8.50 \mathrm{~m}$ de largura e $12.80 \mathrm{~m}$ de altura, foi dedicada a Santa Maria da Caridade e consagrada ao amor de Deus pela humanidade. Era esse o tema que Giotto deveria explorar nos afrescos que decorariam suas paredes. Assim, perguntamo-nos: como Giotto recebeu essa encomenda e realizou a tarefa que lhe foi solicitada? É preciso considerar que, como Baxandall (1991) alerta, as pinturas eram produtos de práticas comerciais muito bem estabelecidas:

\begin{abstract}
De um lado, o pintor que realizava o quadro ou, ao menos, supervisionava sua execução. De outro, alguém que o encomendava, fornecia fundos para sua realização e, uma vez concluído, decidia de que forma usá-lo. Ambas as partes agiam de acordo com as instituições e convenções - comerciais, religiosas, perceptivas, sociais, na acepção mais ampla do termo - que eram diferentes das nossas e influenciaram suas relações em comum. (BAXANDALL, 1991, p. 11).
\end{abstract}

Baxandall (1991) explica que os acordos entre o pintor e o cliente eram devidamente registrados em contratos, nos quais eram especificados vários detalhes das pinturas, inclusive os desenhos que deveriam compor o quadro, as cores usadas e a qualidade das tintas. Segundo Duby (1993, p. 193), nesses contratos não constavam apenas “[...] o preços e os prazos de entrega, mas a quantidade de material, os pormenores da execução, finalmente, e sobretudo, o tema geral da obra, a ordenação da composição, a escolha das cores, a disposição das personagens, os gestos, a atitude". Como se vê, o documento era minucioso, de forma a não deixar nenhum detalhe escapar e a condicionar a criação do artista ao total gosto do mecenas. Portanto, ao receber a encomenda, Giotto teve que considerar os desejos de Enrico ao contratar os dois artistas mais renomados da época: uma decoração grandiosa para ser exibida à sociedade padovana. Essa era a ambição do banqueiro, mas a justificativa explicitada era a salvação da alma do pai, que praticara o pecado da usura. Essa justificativa estava perfeitamente de acordo com o pensamento da época. Para aqueles que tinham enriquecido com "[...] cobrança - na realidade com agiotagem -, gastar seu dinheiro financiando igrejas e obras de arte embelezar o patrimônio público era, por sua vez, um prazer e uma virtude necessária, uma justa indenização à sociedade, algo entre uma doação caridosa e o pagamento de taxa ou de impostos à Igreja" (BAXANDALL 1991, p. 13). Assim, Giotto deveria realizar uma decoração grandiosa que evidenciasse a caridade de Enrico e a salvação da alma de Reginaldo por meio da exaltação da representação da Virgem. Por seu lado, além da necessidade de atender a esses desejos, Giotto deve ter se deparado com outras questões de ordem particular. Vejamos.

Era comum serem indicadas a "[...] a dedicação, a modéstia, as virtudes do artífice medieval, que não desejava outra recompensa senão a divina, a quem repugnava exaltar o seu próprio nome e que vivia, humilde e feliz, no seu ambiente, tendo por única ambição participar no grande esforço colectivo de exaltação da fé" (CASTELNUOVO, 1989, p. 145). No entanto, isso pouco correspondia à realidade, segundo o autor, pois, apesar do grande número de pinturas anônimas, muitas foram assinadas. Uma das razões para a permanência do anonimato das pinturas foi a hierarquia dos ofícios que colocava à frente dos pintores o arquiteto e o ourives: os pintores não tinham reconhecimento social. A valorização dos pintores só ocorreu por meio do que se pode "[...] chamar de aliança dos artistas com os intelectuais, os liberatos, que são os guardas e os legisladores desse domínio privilegiado a que, durante séculos, só os cultores das artes liberais tiveram acesso" (CASTELNUOVO, 1989, p. 161). Tentativas de aproximação 
dos artífices com os intelectuais podem ser observadas nos séculos XII e XIII, quando o termo doctus foi usado para identificar alguns deles e retirá-los da posição subalterna ocupada pelas artes mecânicas. No entanto, foi Dante que auxiliou o reconhecimento desses artistas ao mencionar o nome de Oderisi da Gubbio e Franco Bolognese, miniaturistas, e de Cimabue e Giotto no décimo primeiro canto da Divina Comédia. O fato de o nome desses artistas serem citados no mesmo texto em que aparecem intelectuais significa o início de um reconhecimento promovido pelo "[...] peso da arte profundamente inovadora de Giotto, em redor do qual depressa se cria uma rede de cumplicidades e de admiração" (CASTELNUOVO, 1989, p. 161). Assim as palavras de Dante e a arte de Giotto formam um dueto que aproxima as artes figurativas "[...] das artes liberais, depois de um longo esforço de auto legitimação que os artistas tinham levado por diante, realçando, nas suas assinaturas, o caracter erudito, não mecânico, mas intelectual, da sua forma de trabalhar" (CASTELNUOVO, 1989, p. 162).

As questões apresentadas por Castelnuovo (1989) são importantes para refletirmos sobre as inquietações de Giotto. Entendendo que o objeto é fruto de uma ação consciente e que a situação do artesão e de sua atividade não estavam alheias ao produto da criação, podemos supor hipoteticamente que Giotto aspirava reconhecimento pelo seu trabalho e que esse desejo influenciava seu processo de criação. Mais, se, como vimos com Castelnuovo (1989), o caminho era igualar pintura e artes liberais, ele tinha a intenção de expor a atividade intelectual em suas pinturas. Aceitando essa premissa como verdadeira, observamos que, para atender à encomenda de Enrico e ao mesmo tempo seus anseios de artista, Giotto afrescou na Cappella degli Scrovegni a Anunciação da Virgem, pintando-a sobre a parede do altar, em oposição ao afresco do Juízo Final, ou Universal, pintado na parede da entrada da capela. Unindo essas representações, o artista colocou cenas da vida de Maria e de Jesus sustentadas por uma base compostas por vícios e virtudes. Com essa organização, Giotto pode ter querido sugerir os planos de Deus como reflexão aos homens. No entanto, todas as narrativas afrescadas nas paredes da capela já eram de conhecimento do público, que internamente tinha uma imagem própria da cena. Como Baxandall (1991, p. 53) lembra, quem recebia os produtos das encomendas

[...] praticava exercícios espirituais que exigiam um alto grau de precisão na visualização, ao menos dos episódios principais da vida de Cristo e Maria. Para adotar uma distinção teológica, as visualizações do pintor eram exteriores e as do público interiores. A mente do público não era uma tábua rasa sobre a qual se podiam imprimir as representações que o pintor fazia de uma história ou de um personagem, mas um órgão ativo de visualizações interiores com o qual cada pintor devia estar familiarizado.

Assim, a representação de Giotto não poderia contemplar as diferentes cenas imaginadas por cada um dos que receberiam suas pinturas. Dessa forma, ele precisava despertar 'algo' que agradasse a todos, pois quem consagraria a magnitude de sua obra seria o público, incluindo Enrico e seus pares, o clero e o povo. Como Giotto resolveu essa questão?

Com o intuito de investigar esse assunto, passamos a examinar a organização dos afrescos na Cappella degli Scrovegni como a possibilidade de reflexão filosófica.

\section{A cappella degli Scrovegni: um exercício filosófico}

Giotto di Bondone pode ser considerado uma exceção entre os artistas de seu tempo, tendo em vista a condição social que alcançou. Por seu talento, tornou-se rico e renomado artista, contrariando a ordem social da profissão, na qual os artistas, na maioria das vezes, 
viviam como empregados domésticos dos mecenas, mantendo-se ignorados, já que o valor era tributado à obra e não ao produtor ${ }^{7}$.

Em virtude de sua fama, o pintor manteve relações com pessoas de diferentes níveis sociais, como intelectuais, religiosos e mercadores. Por meio desses relacionamentos, é possível que o artista tenha entrado em contato com as tendências filosóficas de sua sociedade, mesmo porque a Florença de 1300 apresentava características diferentes das de outras cidades. Burckhardt (2009) auxilia-nos a entender esse diferencial florentino ao expor que:

[...] àquela época em Florença, todos podiam ler, que até mesmo os arrieiros cantavam as canzoni de Dante e que os melhores manuscritos italianos de que ainda dispomos teriam pertencido originalmente a artesãos florentinos; teria sido possível então - dizem eles - o surgimento de uma enciclopédia popular, como o Tesoro de Brunetto Latini, e tudo isso teria tido por base uma força e firmeza de caráter resultante da participação de todos nos negócios de Estado, do comércio, das viagens e, principalmente, da sistemática eliminação de todo o ócio - fatores que vicejavam na Florença de então. Além disso - prossegue a argumentação -, os florentinos eram à época respeitados e de grande serventia no mundo todo, não em vão sendo chamados pelo papa Bonifácio VIII, naquele mesmo ano, o quinto elemento (BURCKHARDT, 2009, p. 198, grifo do autor).

Nesse contexto, é admissível pensar que, na organização dos afrescos, Giotto pautou-se em questões filosóficas, pois essas circulavam pelas ruas das cidades italianas. Assim, pretendemos, neste momento, fazer um exercício reflexivo por meio da disposição das imagens dos vícios e virtudes na cappella dell'arena, tendo em vista a inquietação ${ }^{8}$ : por que o artista colocou as virtudes cardeais mais próximas do altar e as teologais, que são de inspiração divina, distantes do local mais sagrado dentro das igrejas?

\footnotetext{
${ }^{7}$ Com base nas informações de Castelnuovo (1989, p. 161-162), podemos dimensionar o respeito que Giotto alcançou em sua época: “A forma como o seu nome e as suas obras são apresentados nos testemunhos da época é um índice da sua fama extraordinária: há um testamento de 1312 que evoca o Crucifixo de Santa Maria Novella, pintado pelo egrégio pintor Giotto e, em 1313, um literato muito interessado por pintura — Francesco da Barberino - mencionara a Inveja, pintada no pedestal da capela dos Scrovegni. Em 1330, enquanto trabalha em Nápoles, é apontado como familiar do rei, protopictor e protomagister e, por ocasião da sua ida para Florença, três anos antes da sua morte, há quem declare solenemente que não há ninguém mais capaz do que Mestre Giotto e que, graças ao facto de ele se ter fixado em Florença, muito aproveitarão com a sua ciência e com os seus ensinamentos e a cidade ficará mais bela. Giotto é chamado a Florença para ser investido do cargo de arquitecto da comuna, o que significa que se, por um lado, esse cargo era o mais elevado que a comuna podia oferecer-lhe, por outro lado, reconhecia-se que a sua competência gráfica e projectual podia ser aplicada em diferentes domínios".

${ }^{8}$ Sobre esses estudos ver Erickson (1995) ou sua tradução em Lycurgo (2004).
} 


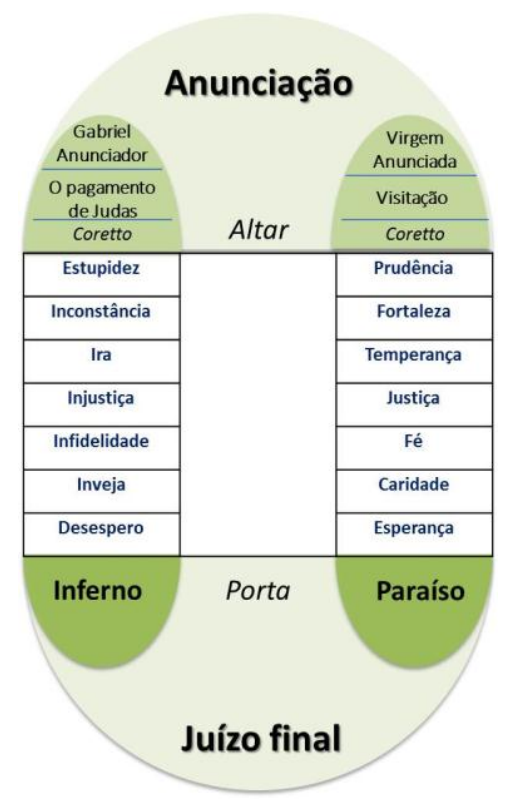

Figura. Giotto di Bondone. Distribuição das virtudes e dos vícios na Cappella degli Scrovegni. Fonte: Elaborado pela autora.

Nesse questionamento, o centro da indagação é o altar, mas podemos pensar por outro caminho. Considerando o pressuposto de que a Cappella degli Scrovegni apresenta-se ao fiel como uma possibilidade de reflexão sobre sua vida, o centro da reflexão seria o fim, a salvação. Nesse sentido, o altar não seria o ponto de referência para analisar a disposição dos vícios e virtudes e sim o Juízo Final.

Essa possibilidade é admissível se nos reportarmos aos ensinamentos de Tomás de Aquino que, ao refletir sobre o fim último do homem, revela-nos que esse fim é a bemaventurança, mas sua conquista depende das ações humanas. O Monge apresenta uma distinção entre ações do homem e ações humanas, cuja compreensão é importante para entendermos a disposição dos vícios e virtudes, bem como dos demais afrescos da capela. Tomás de Aquino explica que as ações humanas são consideradas assim pelo uso da razão, por meio da qual o homem pode ter domínio de seus atos.

Ora, o homem tem domínio de suas ações pela razão e pela vontade. Donde será chamada de livre-arbítrio a faculdade da vontade e da razão. Assim, sendo, são propriamente ditas humanas as ações que procedem da vontade deliberada (TOMÁS DE AQUINO, Suma Teológica, I-II, q.I, a.I, resp., grifo do autor).

Tomás de Aquino admite a existência de outras ações que são próprias do homem como, por exemplo, a digestão e a percepção de som, mas isso também pertence às demais criaturas irracionais, portanto só são humanos os atos do homem enquanto homem, ou seja, provenientes da razão. Portanto, se o ato humano é proveniente da vontade deliberada isso significa que o homem tem total responsabilidade por ele. $\mathrm{O}$ ato humano é consciente e por ser consciente, tem em vista o fim.

Aplicando essa ideia à análise da estrutura organizacional da Capella degli Scrovegni, consideramos que, quando o fiel caminha para o interior da capela, tem à sua frente a 
representação de Deus presidindo a Anunciação, a causa primeira das narrativas expressas naquelas paredes. No impulso de se aproximar da Anunciação, o fiel caminha em sua direção, mas, ao fazê-lo, vai perdendo a visibilidade da pintura em sua totalidade. Ao tentar retomar a visão ampla da capela, o fiel se vira para a porta de entrada, deparando-se com o Juízo Final, cujo centro é a imagem de Jesus, o Deus Juiz que julga os vivos e os mortos. Portanto, o retorno à causa - Deus (anunciação)- requer o caminhar para o fim - Deus (Cristo no juízo final). $\mathrm{O}$ retorno é condicionado pelo caminhar, ou ação humana, que é fruto da vontade e da razão; por isso, o homem pode tender para um dos lados da Cappella degli Scrovegni, para os vícios ou para as virtudes.

Nessa perspectiva, podemos supor que a pintura de Giotto sugere o caminho virtuoso como aquele que conduziria o homem ao seu último fim, a bem-aventurança. Tomás de Aquino explica:

\begin{abstract}
A bem-aventurança é um bem perfeito, que totalmente aquieta o desejo, pois não seria o último fim, se ficasse algo a desejar. O objeto da vontade, que é o apetite humano, é o bem universal, como o objeto do intelecto é a verdade universal. Disto fica claro que nenhuma coisa pode aquietar a vontade do homem, senão o bem universal. Mas tal não se encontra em um bem criado algum, a não ser só em Deus, porque toda criatura tem bondade participada. Por isso, só Deus pode satisfazer plenamente a vontade humana, segundo o que diz o Salmo 102 'Que enche de bens o teu desejo'. Consequentemente, só em Deus consiste a bem-aventurança do homem (TOMÁS DE AQUINO, Suma Teológica, I-II, q.II, a.8, resp.).
\end{abstract}

Tomás de Aquino explica que existem duas formas de entender a bem-aventurança, uma como objeto em si e outra como gozo pela aquisição do objeto: a bem-aventurança em si é Deus e o homem goza da bem-aventurança porque, por seus próprios atos, aproxima-se de Deus. $\mathrm{O}$ Monge afirma que "Sendo a bem-aventurança do homem algo criado nele existente, é necessário afirmar que ela é ação. É a bem-aventurança, ademais, a última perfeição do homem. Cada coisa é perfeita enquanto é ato, pois a potência é imperfeita, sem ato" (TOMÁS DE AQUINO, Suma Teológica, I-II, q.III, a.II, resp.).

Portanto, na Cappella degli Scrovegni, está representado o caminho para o homem atingir a bem-aventurança - Deus representado por Cristo no centro do Juízo Final. Para tanto, ele precisa cumprir o percurso por meio das ações virtuosas expressas nas figurações de cada virtude. Ou seja, Giotto representou a condição para se aproximar do Paraíso, cuja imagem coincide com o término dessas representações. Todavia, a ordem atribuída por Giotto à representação das virtudes pode ser estranhada, já que ele iniciou pelas cardeais e finalizou com a teologais.

Mantendo-nos na perspectiva da ação humana, passamos às seguintes considerações: a construção da capela foi impulsionada pelo desejo de aliviar a alma do patriarca dos Scrovegni pelo pecado da usura e esse desejo pode ser estendido aos demais familiares. Assim, destacamos que a arquitetura da capela foi planejada de forma que a família tivesse uma entrada privada que a colocava diretamente embaixo do altar, acima do qual está pintada a Anunciação. Para ocupar seus lugares privativos, os Scrovegni tinham que se voltar para o fundo da capela, onde está o afresco do Juízo Final. Dessa forma, eles caminhavam primeiro pelos vícios e virtudes tendo à frente a visão do fim.

Podemos supor, portanto, que o artista figurou o caminho da salvação, sendo este iniciado pelas virtudes cardeais, aquelas que seriam adquiridas pelo hábito. Tomás de Aquino, 
ao apresentar o conceito de hábito, baseia-se em Aristóteles e define-o como aquisição de 'algo'.

Dessa forma, podemos pensar que as virtudes cardeais foram colocadas antes da teologais por serem adquiridas pelo hábito, ou seja, pelo exercício da ação humana. As virtudes adquiridas pelo hábito aperfeiçoam o homem, auxiliando-o no caminho para a bemaventurança, mas somente elas não são suficientes para alcançá-la. O monge explica a duplicidade da bem-aventurança humana: “[...] uma é proporcional à natureza humana, ou seja, pode o homem consegui-la pelos princípios de sua natureza; a outra supera sua natureza e só pode se alcançada por graça divina, por certa participação da divindade" (TOMÁS DE AQUINO, Suma Teológica, I-II, q.62, a. I, resp.). Dessa perspectiva, para alcançar a bemaventurança perfeita, aquela que não se alcança em vida, é preciso o auxilio de Deus, que acrescenta alguns princípios, que,

[...] se chamam virtudes teologais, primeiro por terem Deus como objeto, no sentido que nos orientam retamente para ele; depois, por nos serem infundidos só por Deus; e, finalmente, porque essas virtudes são transmitidas unicamente pela revelação divina, na Sagrada Escritura (TOMÁS DE AQUINO, Suma Teológica, I-II, q.62, a.1, resp.).

As virtudes teologais são nominadas de fé, esperança e caridade. Sua denominação, ordem e lócus de ação são abordados na seguinte passagem:

\begin{abstract}
Primeiramente, no que diz respeito ao intelecto, são acrescentados ao homem e apreendidos por iluminação divina alguns princípios sobrenaturais, que são o conjunto do que se deve crer, o objeto da fé - Em segundo lugar, a vontade se ordena para o fim sobrenatural, seja pelo movimento de intenção que tende para esse fim, como para algo possível de se obter e isso é a esperança; seja por uma como união espiritual, pela qual a vontade é de certa forma transformada nesse fim, o que se concretiza pela caridade (TOMÁS DE AQUINO, Suma Teológica, I-II, q. 62, a.3, resp.).
\end{abstract}

Assim, podemos entender que o fato de Giotto tê-las pintado mais próximas do Paraíso pode indicar que, sem o auxilio de Deus, o homem não pode alcançar a bem-aventurança perfeita. Todavia, a ordem das virtudes teologais também nos inquieta: por que Giotto inverte a posição das duas últimas virtudes, pintando a caridade antecedendo a esperança? De acordo com a premissa de que Giotto está se concentrando no agir humano, é aceitável pensar que a bem-aventurança que o homem pode alcançar em vida - bem-aventurança imperfeita - não elimina o desejo/apetite da bem-aventurança perfeita, que só será atingida quando o homem encontra Deus. Na representação de Giotto, a bem-aventurança perfeita pode ser entendida como a absolvição do homem no Juízo Final, o que lhe permitiria usufruir da visão de Deus no Paraíso. Nesse sentido, a ação humana não tem seu fim nas virtudes teologais e sim na obtenção da vida eterna no Paraíso. Portanto, a ordem que ele deu às virtudes teologais pode ser pensada por meio da objeção apresentada pelo Mestre Tomás: "Além disso, Agostinho diz que 'ninguém pode amar aquilo em cuja existência não crê; mas se crê e ama, agindo bem, chega também a esperar'. Logo, parece que a fé precede a caridade e esta precede a esperança" (TOMÁS DE AQUINO, Suma Teológica, I-II, q.62, a.4, obj.2). Na resposta a essa argumentação, o Monge explica que Agostinho está se referindo à esperança com relação a um mérito, que ele denomina 
de 'esperança formada', mas na sequência menciona que a esperança pode anteceder a caridade não por um mérito adquirido mas pelo que se espera ter. Dessa forma, Tomás de Aquino não exclui a possibilidade de a caridade anteceder a esperança, pensamento que é explicado na questão 25, na qual o Monge comenta as quatro principais paixões do irascível: "O temor e a esperança são principais não como completivas de modo absoluto, mas porque são completivas no gênero do movimento apetitivo de alguma coisa, relativamente ao bem, o movimento começa no amor, continua no desejo e termina na esperança;" (TOMÁS DE AQUINO, Suma Teológica, I-II, q.25, a.4, resp.). Assim, podemos supor que a caridade indicada por Giotto é um elemento inserido por Deus, mas que não é absoluto em vida, portanto produz esperança de alcançar sua plenitude na bem-aventurança completa, ou seja, no Paraíso.

Todavia, do lado oposto do Paraíso - do lado esquerdo de Cristo no Juízo Final -, vemos o inferno repleto de pessoas em castigos eternos. Essa observação nos direciona para o seguinte raciocínio: Tomás de Aquino (Suma Teológica, I-II, q.1, a.5, resp.), ao responder se há muitos últimos fins para um só homem, afirma categoricamente que não. Então, se há um só fim para o homem e ele se move em razão desse fim, por que uns têm como destino final o Paraíso e outros o Inferno? A resposta pode ser encontrada no artigo VII da mesma questão. Tomás de Aquino explica que há um só último fim para todos os homens, mas é preciso considerá-lo por duas maneiras: "[...] segundo a razão do último fim, ou segundo aquilo em que se encontra a sua razão" (TOMÁS DE AQUINO, Suma Teológica, I-II, q.1, a.7, resp.). Na sequência, ele explica que, segundo a razão, não há diferença, pois todos desejam a perfeição do último fim; no entanto, com relação ao lugar onde se deposita a razão, existem diferenças. Assim, "[...] alguns desejam as riquezas como o bem perfeito, outros o prazer, outros qualquer outra coisa" (TOMÁS DE AQUINO, Suma Teológica, I-II, q.1, a.7, resp.). Dessa forma, podemos entender que aquelas pessoas pintadas no inferno de Giotto depositaram a razão do sumo bem em coisas que não correspondiam com a razão do último fim. Essa ideia justificaria que os vícios tenham sido representados do mesmo lado do inferno. O caminho da danação é percorrido, passo a passo, pelas ações viciosas dos homens e mulheres que se tornam pecadores mediante suas condutas. Essa questão se torna mais evidente quando olhamos atentamente para cada representação. Tomemos como exemplo a imagem da inveja.

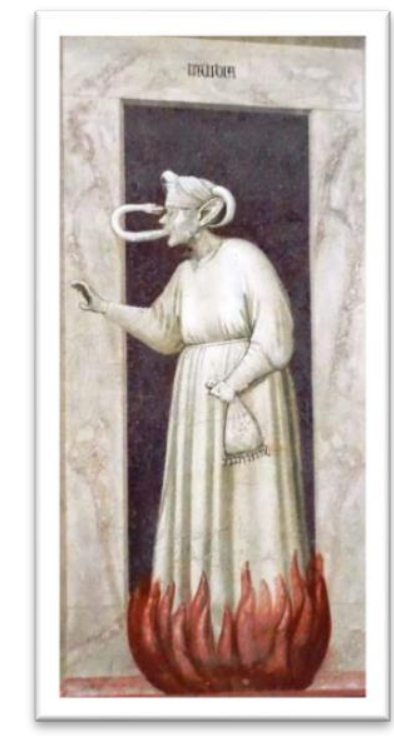

Figura. Giotto di Bondone. Inveja. Ciclo dos vícios (afrescos, 55 X 1,20 cm - parede esquerda, $4^{\mathrm{a}}$ fileira). Cappella degli Scrovegni, Padova /Itália.

Fonte: Acervo da autora (2014). 
Inveja, invidia em latim, significa não ver. Observamos que Giotto representou esse vício por meio das causas que conduzem os homens à cegueira da inveja. Vemos nesse quadro uma velha que está com a mão direita em posição que nos dá impressão do desejo de querer pegar algo alheio, enquanto sua mão esquerda segura firmemente uma bolsa. Essa representação nos remete ao conceito de inveja apresentado por Tomás de Aquino. Ele explica que ela se manifesta em relação ao bem de outras pessoas, de forma que o invejoso "[...] se entristece com o bem alheio, enquanto esse impede a própria excelência" (TOMÁS DE AQUINO, Suma Teológica, I-II, q.84, a.4, resp.). Presumimos que essa tristeza seja aflorada pela atenção dada aos falatórios que entram pelas enormes orelhas que Giotto concedeu à velha. A inveja é figurada por meio da venenosa língua em forma de serpente que se volta contra a própria pessoa, cegando-a de tal forma que ela não percebe que está no centro de uma fogueira. A estrutura adotada pelo pintor, que relaciona o conceito do vício com a ação viciosa e a consequência da ação em si, pode ser observada, também, nas demais representações que se tornam quase reais aos olhos do observador. A altura das figuras e a técnica monocromática empregada pelo artista propicia a ilusão da tridimensionalidade das esculturas, fazendo com que o fiel se identifique com elas ainda mais. A mesma técnica dos vícios foi adotada para as virtudes, causando a mesma impressão entre as duas representações.

Assim, diante desse paradoxo de causa e efeito, o fiel é convidado a refletir acerca de seus atos, mas sem abandonar a consciência de que Deus está no comando do universo. Dessa forma, Giotto estabeleceu uma conexão entre o mundo terreno e o divino. Ao mesmo tempo em que o artista dialogava com os dois mundos, definia os limites e as funções de cada um deles: Deus no painel da Anunciação governa o mundo terreno e divino, mas o homem, pelas suas ações deliberadamente virtuosas ou viciosas, será julgado por Cristo no centro do Juízo Final. Nesse sentido, ele distinguia os dois hemisférios, e o homem, assim como os elementos de sua vida material, ganhava importância existencial. Há, na Capela degli Scrovegni, uma conciliação entre o humano e o divino, por meio da harmonia que abriga os dois mundos que, respeitosamente, se unem para demonstrar a totalidade que abarca o homem.

\section{Considerações Finais}

Com base nas reflexões desenvolvidas, entendemos que existe a possibilidade de uma aproximação das representações dos vícios e das virtudes de Giotto com o pensamento filosófico do 'último fim do homem'. Essa reflexão, desenvolvida anteriormente por Aristóteles, é retomada com grande intensidade no século XIII pelo mestre dominicano Tomás de Aquino, que a dissemina nos círculos universitários. Aceitando essa questão filosófica como o elo entre as representações giottescas, podemos supor que características como essa tenham contribuído para a elevação do mestre florentino ao nível dos doutos e impulsionado o reconhecimento da pintura como uma atividade intelectual, tirando-a, posteriormente, da marginalidade das artes mecânicas.

Nessa perspectiva, inferimos que o público, ao receber as imagens de Scrovegni, não as defrontou com suas próprias imagens. As representações pictóricas de Giotto provocaram, a nosso ver, uma sensibilização pelo exercício reflexivo e não pelo apelo sentimental, o que estabelece um distanciamento das imagens particulares dos fieis que atendem os propósitos de memorizar as cenas e despertar a piedade necessária nas orações. Não que as representações de Giotto não desenvolvam esse fim, mas elas ultrapassam a finalidade religiosa e expressam os princípios de uma conduta social consciente. Nesse sentido, Giotto, assim como os intelectuais, expõe um princípio educativo, o 'fundamento absoluto' da conduta humana, Deus. Deus, 
fundamento absoluto que fornece os princípios da conduta dos homens, mas que são aceitos ou não, segundo o livre arbítrio de cada um.

Em suma, Giotto, ao realizar o desejo de uma decoração magnífica por parte de Enrico, criou uma obra que o aproxima do patamar dos doutos, em harmonia com os preceitos medievais de Deus como bem-aventurança, ou último fim dos homens.

\section{REFERENCIAS}

BASILE, Giuseppe; BORSELLA, Serenella. Giotto the Srcovegni chapel in Padua. Milão: Skira, 2013.

BAXANDALL, Michael. O olhar Renascente: pintura e experiências social na Itália da Renascença. Rio de Janeiro: Paz e Terra,1991.

BAXANDALL, Michael. Padrões de intenção: a explicação histórica dos quadros. São Paulo: Companhia da Letras, 2006.

BURCKHARDT, Jacob. A cultura do renascimento na Itália: um ensaio. São Paulo: Companhia das Letras, 2009.

CASTELNUOVO, Enrico. O artista. In: LE GOFF, Jacques. O homem medieval. Lisboa: Presença, 1989. p. 145-162.

DUBY, Georges. O tempo das catedrais: arte e sociedade 980-1420. Lisboa: Estampa, 1993.

JACOBUS, Laura. Giotto and the Arena Chapel: art, architecture and experience.

Michigan: Harvey Miller Publishers, 2008.

LAUAND, Jean. Tradução e estudos introdutórios. In: TOMÁS DE AQUINO. Sobre o ensino (De magistro). Os sete pecados capitais. São Paulo: Martins Fontes, 2004.

PISANI, Giuliano. I volti segreti di Giotto: le rivelazioni dela Cappella degli Scrovegni. Italy: Rizzoli, 2011.

TOMÁS DE AQUINO. Suma teológica. Obra completa. Disponível em: <http://permanencia.org.br/drupal/node/8>. Acesso em: 07 fev. 2015.

TOMÁS DE AQUINO. Suma Teológica. Os hábitos e as virtudes. I-II parte. Vol. IV. São Paulo: Loyola, 2003.

WOLF, Norbert. Giotto. Lisboa: Taschen, 2007. 